\title{
GENDER AND AGE DIFFERENCES IN CONFLICT MANAGEMENT WITHIN SMALL BUSINESSES
}

\author{
WERNER HAVENGA \\ Department of Human Resource Management \\ University of Johannesburg \\ South Africa \\ Corespondence to: Werner Havenga \\ e-mail: whavenga@uj.ac.za
}

\begin{abstract}
The objective of this exploratory study was to establish, through the application of the Rahim Organisational Inventory (ROC II) instrument, how the gender and age status of owners/managers of small businesses relate to the application of different conflict-handling styles. The sample of 68 participants was taken using a convenience sampling technique to ensure representation from the strata of the 102 small businesses. Analysis of variances was used to determine if differences exist in conflict-handling styles within the gender and age status groups. The results of the statistical analysis done revealed that slight to significant variances were found, which are discussed accordingly.
\end{abstract}

Keywords: Conflict-handling styles, interpersonal conflict, age, gender, small business

There is no shortage of definitions for the term conflict. Ting-Toomey (1985, p.72) defines conflict as a form of intense interpersonal and/or intrapersonal dissonance between two or more interdependent parties based on incompatible goals, needs, desires, values, beliefs, and/or attitudes. Rahim and Magner (1995, p.722) regard conflict as an interactive process manifested in incompatibility, disagreement or dissonance within or between social entities.

Through the years different schools of thought on conflict have been developed and applied. According to Rahim (1992, p.4) the traditional approach follows the belief that all conflict is considered to be negative and destructive, and as such should be avoided. The avoidance of conflict thus leads to the focus being shifted from managing it to trying to prevent it from occurring. The studies of Elton Mayo during the 1920s gave rise to the human relations approach, which states that conflict is considered to be a natural phenomenon and can thus not be eliminated, but should be viewed as making a contribution to increasing the performance within a group or organisation (Robbins, 1998, p.434-435). The inter-actionist approach developed the philosophy among modern theorists that "healthy" organisations seek to increase intra-organisational conflict, thus actively encouraging conflict in the workplace. The rationale behind this is that groups that are too harmonious and peacefully static, are nonresponsive and inadaptable, and that moderate levels of conflict optimise productivity (Rahim, 1992, p.5).

In order to counteract the negative or positive effects of conflict, appropriate conflict-handling styles have to be implemented. Conflict management is what people who experience conflict intend to do, as well as what they actually do (Van de Vliert, 1997). It refers to the strategies implemented by members aimed at reducing or solving conflict.

It is contended that conflict is an important theme to study in both business organisations and in close working relationships. Conflict, if perceived negatively as with the traditional approach, may impact on productivity, work performance and on job satisfaction. In close working relationships it can also be a threat to satisfaction and the endurance of interpersonal relationships. Such negative outcomes necessitate that conflict be studied empirically by gathering data on its appearance, causes, and on its emotional, cognitive motivational and behavioural aspects (Nauta \& Kluwer, 2004)

During the past few decades researchers have taken a keen interest in conflict in the workplace and its impact on organisations. Amongst others, studies were conducted on interpersonal conflict-handling styles (Jehn 1997; Fillbeck \& Smith 1997; Neale \& Northcraft, 1999), conflict resolution strategies (Van De Vliert \& Euwema, 1994), conflict and justice (Ohbuchi, Suzuki \& Hayashi, 2001), theories of managing conflict (Rahim, 2002), conflict of interests and objectives (Vilaseca, 2002) and managing constructive (functional) and destructive (dysfunctional) conflict (Jehn, 1995; Pelled, Eisenhardt \& Xin, 1999). It seems from literature that conflict management strategies or techniques have been studied systematically (Havenga, 2005).

Rahim (2002) suggested that conflict management strategies should involve recognition of the different types of conflict which may have a positive or negative impact on individual and group performance. Dimensions of conflict which are useful for conflict management include: task and emotional conflict (Ross \& Ross, 1989); cognitive and affective conflict (Amason, 1996) and task and relationship conflicts (John, 1997). Affective and substantive conflict account for differential effects in organisations and also affect the management of interpersonal conflict within the work environment (Jehn, 1995; Pearson, Ensley \& Amason, 2002) According to Rahim (2002) the two dimensions of conflict, substantive and affective, are positively correlated which means that in the process of enchaining substantive conflicts, affective conflict may also be increased.

One of the problems of managing conflict, as suggested by Applebaum, Abadallah \& Shapiro (1999) is that managers spend $20 \%$ of their time resolving conflict. Recognition of the different types, as well as the dimensions of conflict in the workplace is valuable in managing conflict. However, being aware of the extent of conflict at various levels of an organisation and of the various conflict-handling styles is crucial for understanding the management of organisational conflict (Rahim 1986). What became evident from the literature survey is that almost all studies concentrate on conflict, whether generic or in a work environment, in organisations and groups not linked to small businesses. Very few conflict studies have been conducted in small- and medium- sized enterprise environments. These environments, according to Havenga (2005) are closely knit and have an impact on the behaviour of individuals that may differ from that in larger organisations. Recent research has focused on conflict of interests and objectives (Vilaseca, 2002); team building and conflict management techniques (Filbeck \& Smith, 1997); influences of work/family conflict on job satisfaction and quitting intentions among business owners (Boles, 1996); the phenomenon of substantive conflict in small family firms (Davis 
\& Harveston, 2001); and conflict management strategies in small family businesses (Sorenson, 1999).

Personality characteristics, interpersonal needs, individual behaviour (Lotriet, Crafford \& Visser, 2001), organisational status (Brewer et al., 2002), emotions (Bodtker \& Jameson, 2001), power, rewards, beliefs and basic values (Weider-Hatfield \& Hatfield, 1995; Slabbert 2002) also influence the choice of conflict-handling styles applied.

Apart from this Brenner, Tomkiewics and Schein (1989) also bring into the equation the possibility that the sexes differ in their ability to manage conflict. Gender role, organisational status and conflict-management styles are also addressed by Brewer, Mitchell \& Weber (2002). They focused more broadly on the differences between sexes in dealing with conflict, and consider two theoretical perspectives which provide a more clear and effective way of explaining individual differences in conflict handling styles. The one perspective highlights the influence of gender role orientation and the other organisational status. Some older studies suggest that females have a more cooperative attitude to conflict handling than males (Rahim, 1983), whilst Beddell and Sistrunk (1973) suggested that females are more competitive. The gender role perspective, according to Brewer et al. (2002) conceptualises masculinity and femininity as independent dimensions. Following this role perspective the competitive or dominating behaviour appears to be consistent with the male role. Obliging and avoiding behaviour on the other hand is more consistent with females.

\section{Gender differences in conflict-handling styles}

It appears that while few researchers have studied the relationship between conflict- handling styles and gender roles, those who have reported masculine individuals adopting a dominating style (Portello \& Long, 1994; Brewer et al., 2002) and females an avoiding conflict-handling style (Brewer et al., 2002). In a study conducted by Antonioni (1998) it was revealed that gender in general had little relationship with the variance of the conflict-management style. Gender was non-significant in all models after controlling for the personality variables. Korabik et al (1993) came to the same conclusion a few years earlier when they stated in their study that women managers do not differ from their male counterparts in preferred conflict-handling style. Other studies such as that of Dean (1992) verified that in small family businesses most of the owners made use of the authority (dominating) style to resolve disputes. The compromising style was used to a lesser extent. Sutschek (2001) in turn found in her study that females did not use the integrating and obliging conflict-handling styles more often than males when confronted with the same conflict scenario. Male managers did not use the competitive conflict-handling style more often than female managers. Males prefer to use the dominating conflict-handling style before utilising the avoiding strategy. Females, on the other hand, prefer the avoiding instead of the dominating conflicthandling style. Research done by Sorenson and Hawkin (1995) also found more similarities between preferred conflicthandling styles for managers of both sexes when dealing with the same conflict situation.

It is evident that studies done on conflict-handling styles between male and female participants in the business environment has provided inconsistent results when compared to other studies done in the same field. Therefore, it is firstly the purpose of this study to establish if and how gender influences the implicit or explicit choice of conflict-management styles of owners/managers of small businesses. In light of this the first hypothesis will be tested:

\section{Hypothesis 1}

There is a statistically significant gender difference in conflictmanagement styles used by owners (managers) when dealing with subordinates in small businesses.

\section{Age differences in conflict handling-styles}

Within the unique environment of small businesses, which, in most cases, are small family firms, interpersonal conflict could be detrimental to the success of the business. Although many of these businesses find ways to manage such conflict in the workplace, very little is known about how it is managed or the impact of conflict-management strategies on the business (Lee \& Rogoff, 1996). It is believed that shifting the focus from the elimination of conflict to the management of conflict requires a better understanding of the conflict phenomenon (Thomas, 1992). It could be assumed that age, as part of the interpersonal conflict phenomenon in the workplace, also influences the style of handling conflict. It became evident from the literature survey that in contrast to gender issues, almost no specific studies have been conducted on age and its effect on the application of different conflict-handling styles.

Antonioni (1998) came to the conclusion that age in general had little relationship to the variance of the conflict-management style. It was found that age was significantly associated with only the integrating and avoiding conflict handling styles.

Therefore it is secondly the purpose of the study to establish how age influences the implicit or explicit choice of conflicthandling styles of owners/managers of small businesses, and additionally whether age is significantly associated with only the integrating and avoiding conflict management styles, as claimed in the study of Antonioni (1998). With this in mind the second hypothesis will be tested:

Hypothesis 2

There is a statistically significant difference in the conflictmanagement style used by owners of different ages in small businesses.

\section{RESEARCH DESIGN}

\section{Research approach}

A quantitative approach was followed in this exploratory study. The primary data was generated using a standardised instrument in a field survey design. Results were presented by means of descriptive group statistics and correlations.

\section{Research method}

Participants and sampling strategy

The participants used for the study consisted of 68 Caucasian owners/managers of small businesses. This sample was taken using a convenience sampling technique to ensure representation from the strata of the 102 small businesses owners/managers, which was identified in a demarcated geographical area in South Africa. The participants were solicited to complete the conflict survey questionnaire. The resultant response rate of useable questionnaires was $82.4 \%$. This rate can be considered acceptable, taking into account that low response rates are common in small business research (Sorenson, 1999). Sorenson (1999) had a usable sample of 59 in his study.

Characteristics of the sample are detailed in Table 1. Biographical data indicate that $73.2 \%$ of the respondents were males. Participants who had been in business less than 11 years totalled $48.2 \%$ and those more than 11 years $51.8 \%$. Respondents came from different age groups with $30.4 \%$ being younger than 36 years, those between 36 and 45 totalling $28.6 \%$ and $41.0 \%$ were older than 46 years. Data further revealed that $57.2 \%$ of the businesses employed 1-10 people and $42.8 \%$ employed more than 10. The industries with the largest representation in the sample were the retail (39.3\%), automobile (19.6\%) and restaurant industries (7.1\%). As can be seen from the statistics the gender composition of the sample was strongly biased toward males. There is also a skewed trend towards older participants with $69.6 \%$ above 36 years. Vinger \& Cilliers (2006) state in their 
TABLE 1

Demographics of participants

\begin{tabular}{|c|c|c|c|c|c|}
\hline & $\mathbf{N}$ & $\%$ & & $\mathbf{N}$ & $\%$ \\
\hline Gender & & & Academic qualification & & \\
\hline Male & 41 & 73.2 & Grade 12 or lower & 14 & 25.0 \\
\hline \multirow[t]{2}{*}{ Female } & 15 & 26.8 & Certificate/diploma & 17 & 30.4 \\
\hline & & & Graduate/Postgraduate & 25 & 44.6 \\
\hline Ethnicity & & & Home language & & \\
\hline \multirow[t]{2}{*}{ Caucasian (White) } & 56 & 100.0 & English & 12 & 27.3 \\
\hline & & & Afrikaans & 44 & 72.7 \\
\hline Years in business & & & Number of employees & & \\
\hline $1-4$ years & 11 & 19.6 & 1-5 employees & 16 & 28.6 \\
\hline $5-10$ years & 16 & 28.6 & 6-10 employees & 16 & 28.6 \\
\hline $11-15$ years & 11 & 19.6 & $11+$ employees & 24 & 42.8 \\
\hline $15+$ & 18 & 32.2 & & & \\
\hline Industry & & & Age group & & \\
\hline Steel & 3 & 5.4 & Younger than 36 & 17 & 30.4 \\
\hline Furniture & 2 & 3.5 & $36-45$ & 16 & 28.6 \\
\hline Paint & 2 & 3.5 & Older than 45 & 23 & 41.0 \\
\hline Automobile & 11 & 19.6 & & & \\
\hline Restaurant & 4 & 7.1 & & & \\
\hline Retail & 22 & 39.3 & & & \\
\hline Financial & 1 & 1.8 & & & \\
\hline Hotel & 1 & 1.8 & & & \\
\hline Tourism & 0 & - & & & \\
\hline Agriculture & 0 & - & & & \\
\hline Health & 2 & 3.5 & & & \\
\hline Other & 8 & 14.4 & & & \\
\hline
\end{tabular}

study that the age group 31 to 65 years can be considered characteristic of leadership levels in organisations.

\section{Measuring instruments}

Measuring instruments considered for this study include Blake and Mouton's (1964) Two-dimensional grid, Hall's (1969) Conflict Management Survey model, the Thomas-Kilmann (1974) Conflict Mode, the Dutch Test for Conflict Handling (Euwema \& Van de Vliert, 1990), and the Rahim Organisational Conflict Inventory - II (Rahim, 1983). Hall's model proved to have disappointing psychometric qualities (Thomas-Kilmann, 1978). Nauta and Kluwer (2004) also questioned whether the Dutch Test for Conflict Handling model really measured behaviour under all circumstances. While Rahim's ROC-II instrument has also been criticised for the perception that the scale still lacks optimal psychometric properties.

Ben-Yoav \& Bonai (1992) claimed that the Rahim instrument has a higher internal consistency coefficient than models such as the Thomas-Kilmann instrument. The five-factor ROC-II model also has a better fit with data than models of two, three and four conflict-handling style orientations. In recent studies, for instance, Meyer (2004) used four conflict-handling styles and Euwema, Van der Vliert \& Bodtker (2003) seven.

After carefully considering the high reliability coefficients of the ROC-II Instrument it was decided that it would suffice for reaching the objectives of this study. This instrument measures how organisational members manage their interpersonal conflict with superiors, subordinates and peers in a work environment. Five styles of handling interpersonal conflict are measured with 28 items in a standardised questionnaire. This is done on a 5-point Likert-scale. Greater use of a conflicthandling style is presented by a higher score.

The five different areas of conflict-management which are incorporated into the ROC-II instrument include: integrating (high concern for self and high concern for others), dominating (high concern for self and low concern for others), obliging (low concern for self and high concern for others), avoiding (low concern for self and low concern for others), and compromising (intermediate levels of concern for both self and others) (Rahim, 2002; Rahim \& Magner, 1995).

\section{Research procedure}

With the assistance of an academic colleague in the strategic management field, the ROC-II questionnaires were personally distributed to the respondents. At the onset of distribution the owners/managers of the small businesses were briefed individually on the purpose, nature and expected duration for completing the questionnaire. Confidentiality and anonymity were also assured to participants. A period of two weeks was allowed for completion of the questionnaires. Collection of the questionnaires took place at the premises of the various businesses. Participants were then also given the opportunity to clarify any problems experienced with the questionnaire. A follow-up was done after an additional week to collect outstanding questionnaires not completed within the set time limit.

\section{Statistical analysis}

Statistical analysis was carried out with the SPSS Programme (SPSS Inc., 2003). Firstly, factor analysis was done on the data regarding the influence of gender on the usage of one or more of the conflict-management styles. Secondly data was analysed statistically to determine how different age groups use one or more of the five conflict management styles in their interpersonal conflict situations in the workplace. Cronbach's alpha coefficients were computed to assess the validity and reliability of the constructs that were measured in this study. The construct validity was determined by applying factor analysis to the items in question. The face value of the instrument was assured through testing it with specialists in the field.

\section{RESULTS}

\section{Validity of the ROC-II Instrument}

In past studies (Gross \& Guerrero, 2000), Cronbach's alpha coefficient for each of the ROC-II subscales has ranged from $0.77-0.83$ (integrating); $0.68-0.72$ (obliging); $0.75-0.79$ (dominating); $0.72-0.86$ (avoiding) and $0.67-0.76$ (compromising). The analysis in this study yielded an acceptable five-factor solution with all items loading $0.65-0.83$. The lowest reliability value was 0.65 (compromising) and the highest 0.84 (integrating). The lowest value can still be considered to be in the middle order of acceptability. Nunnally \& Bernstein (1994) consider values that vary around 0.50 as being the lower limit of acceptability.

\section{General findings from the study}

Findings revealed that owners/managers in small businesses tend to be more integrating/collaborative $(\mathrm{M}=1.87, \mathrm{SD}=0,87)$ and less dominating/competitive $(\mathrm{M}=2.93, \mathrm{SD}=0,94)$. A study done by Sorenson (1999) with almost the same number of small business owner participants (59 Caucasians), recorded M's and SD's of 4.08 and 0.84 for integrating and 2.3 and 0.94 for dominating. Comparison of descriptive statistics regarding the other three conflict-handling styles showed a reasonably similar trend. Avoiding were $\mathrm{M}=3.20, \mathrm{SD}=0.99$ compared to Sorenson's results of $\mathrm{M}=3.030$ and $\mathrm{SD}=0.89$. Obliging were $\mathrm{M}$ $=2.71, \mathrm{SD}=0.71$ compared to $\mathrm{M}=3.85$ and $\mathrm{SD}=0.81$. In the case of the compromising style the $\mathrm{M}$ was $=2.25$ and $\mathrm{SD}$ was $=0.67$. Soreson recorded $\mathrm{M}=3.65$ and $\mathrm{SD}=0.80$. No distinction was made between gender or age.

\section{Gender differences in conflict-handling}

By comparing the different conflict-handling styles against the background of variable gender in a small business, the findings were as presented in Table 2 .

No significant difference could be found with regard to the different genders. A small effect size of 0.118 was experienced with the integrating variable. All the others, taking into account 
TABLE 2

Descriptive group statistics and directional measures - gender $(\mathrm{n}=56)$

\begin{tabular}{llllllll}
\hline FACTOR & GENDER & $\mathbf{M}$ & $\mathbf{S D}$ & $\mathbf{t}$ & DF & $\begin{array}{l}\text { Sig } \\
\text { (2-TAILED) }\end{array}$ & VALUE \\
\hline Integrating & $\mathrm{M}$ & 1.900 & 0.731 & & & & \\
& $\mathrm{~F}$ & 1.724 & 0.377 & 0.855 & 52 & 0.259 & 0.118 \\
\hline Avoiding & $\mathrm{M}$ & 3.166 & 1.054 & & & & \\
& $\mathrm{~F}$ & 3.256 & 0.851 & -0.278 & 50 & 0.782 & 0.039 \\
\hline Dominating & $\mathrm{M}$ & 2.917 & 0.896 & & & & \\
& $\mathrm{~F}$ & 3.014 & 1.091 & -0.331 & 53 & 0.742 & 0.045 \\
\hline Obliging & $\mathrm{M}$ & 2.707 & 0.689 & & & & \\
& $\mathrm{~F}$ & 2.654 & 0.769 & 0.239 & 53 & 0.812 & 0.033 \\
\hline Compromising & $\mathrm{M}$ & 2.179 & 0.633 & & & & \\
& $\mathrm{~F}$ & 2.285 & 0.535 & -0.559 & 51 & 0.579 & 0.078 \\
\hline
\end{tabular}

0 - 0.1 has no effect and 0.5 has a large effect size, were less than 0.1. Thus, although the variable integrating conflict-handling style proved not to have a significant difference, it did have a small effect-size. The females make use of the integrating style on a more frequent basis than males in order to manage conflict situations in business. The mean for females was 1.724 and for males 1.900 considering that 1 has the highest and 5 the lowest meaning. Both males and females, when measured in terms of significant difference, use all five of the conflict-handling styles to the same extent.

In Table 3 the parametric (Pearson) and non-parametric (Spearman) inter-correlations with normal data distribution were carried out for both gender groups. From this table it is evident that a consistency exists with regard to the intercorrelations, except for the obliging conflict-handling style where a significant negative correlation (-0.583) is registered with the Pearson correlation against the dominating factor at $\mathrm{p}<0.05$. No correlation is recorded in the Spearman case.

Through closer examination of the inter-correlations it was determined that females registered a significant negative correlation (-0.699) between the avoiding conflict-handling style and the integrating style. A significant positive relationship $(0.584)$ is found between the compromising and obliging conflicthandling styles. The negative correlation is due to the fact that in the case of the integrating style a high concern for oneself and for others is dominant.

With the avoiding style a low concern for oneself as well as the other party in the interpersonal conflict situation exists. On the other hand the obliging and compromising styles are closely related in the sense that these styles both have a low to moderate concern for self and the other party. Both are also accommodating with a give-and-take attitude.

The males registered a strong negative correlation (-0.630) between the dominating, integrating and compromising conflict-
TABLE 4

Descriptive statistics - age status $(\mathrm{n}=56)$

\begin{tabular}{lllll}
\hline FACTOR & AGE & $\mathbf{M}$ & $\mathbf{S D}$ & STD. ERROR \\
\hline Integrating & $-36 \mathrm{yr}$ & 1.932 & 0.567 & 0.137 \\
& $36-45$ & 1.993 & 0.699 & 0.180 \\
& $45+$ & 1.795 & 0.740 & 0.154 \\
Avoiding & $-36 \mathrm{yr}$ & 3.274 & 0.805 & 0.195 \\
& $36-45$ & 3.023 & 1.302 & 0.348 \\
& $45+$ & 3.265 & 0.940 & 0.201 \\
Dominating & $-36 \mathrm{yr}$ & 2.623 & 1.041 & 0.252 \\
& $36-45$ & 2.662 & 0.775 & 0.193 \\
& +45 & 3.330 & 0.847 & 0.176 \\
Obliging & $-36 \mathrm{yr}$ & 2.775 & 0.768 & 0.186 \\
& $36-45$ & 2.585 & 0.742 & 0.185 \\
& $45+$ & 2.753 & 0.660 & 0.137 \\
Compromising & $-36 \mathrm{yr}$ & 2.117 & 0.679 & 0.164 \\
& $36-45$ & 2.183 & 0.820 & 0.211 \\
& $45+$ & 2.397 & 0.559 & 0.119 \\
\hline
\end{tabular}

handling styles. The dominating style projects a high concern for oneself and a low concern for others. It is compatible with autocratic authority and forces solutions. A significant positive correlation was found between integrating and obliging (0.480), and compromising $(0.650)$ at the $\mathrm{p}<0.01$. The compromising and obliging (0.404) at the $\mathrm{p}<0.05$ level also reflected a significant positive correlation. By demonstrating supportiveness and acknowledging the concerns of others, the obliging style should contribute to good relationships and cohesiveness (Seymour, 1993).

\section{Age differences in conflict handling}

Comparison of the styles used to manage interpersonal conflict in the workplace against the age-status background variable recorded the statistical results as shown in Tables 4, 5 and 6 . Age groupings used were 36 years and less, 36 to 45 years, and older than 45 years.

A significant statistical difference of $p=0.023$ could be found for the factor dominating within the different age groups. A medium effect size of 0.364 was recorded with the dominating independent (Table 5). Integrating, avoiding and obliging had very small effect sizes ranging between 0.102 and 0.116 , with the compromising dependent (0.187) lying between small and medium effect sizes. All the dependants excluding dominating had effect sizes smaller than $<0.2$ but slightly bigger than $>0.1$. Thus, although the variable dominating conflict-handling style proved to have a significant difference, it was contributed with only a medium effect size. It is also evident that the younger participants, 36 years or less, tend to make more use of the dominating conflict-handling style $(\mathrm{M}=2.623)$ than the $36-45$ years $(\mathrm{M}=2.662)$ and the 45 years and older $(\mathrm{M}=3.330)$ group.

TABLE 3

Parametric and non-parametric inter-correlations of chs's according to gender in small businesses ( $\mathrm{n}=56$ )

\begin{tabular}{|c|c|c|c|c|c|c|}
\hline \multirow[b]{2}{*}{ MALES } & & \multirow[b]{2}{*}{ Integrating } & \multicolumn{3}{|c|}{ FEMALES } & \multirow[b]{2}{*}{ Compromising } \\
\hline & & & Avoiding & Dominating & Obliging & \\
\hline \multirow[t]{2}{*}{ Integrating } & $r$ & & -0.699 ** & -0.320 & 0.303 & 0.242 \\
\hline & Srho & & $-0.641^{* *}$ & -0.288 & 0.441 & 0.174 \\
\hline \multirow[t]{2}{*}{ Avoiding } & r & -0.193 & & 0.085 & 0.283 & 0.025 \\
\hline & Srho & -0.171 & & 0.226 & 0.031 & 0.079 \\
\hline \multirow[t]{2}{*}{ Dominating } & r & $-0.630^{* *}$ & 0.150 & & $-0.583^{*}$ & -0.376 \\
\hline & Srho & $-0.652^{* *}$ & 0.165 & & -0.508 & -0.388 \\
\hline \multirow[t]{2}{*}{ Obliging } & r & $0.480^{* *}$ & 0.282 & -0.167 & & $0.584^{*}$ \\
\hline & Srho & $0.473^{\star *}$ & 0.296 & -0.196 & & $0.594^{*}$ \\
\hline \multirow[t]{2}{*}{ Compromising } & r & $0.650^{* *}$ & -0.080 & $-0.345^{*}$ & $0.404^{*}$ & \\
\hline & Srho & $0.646^{* *}$ & -0.074 & $-0.330^{*}$ & $0.377^{*}$ & \\
\hline
\end{tabular}

$r=$ Pearson parametric correlation.

Srho $=$ Spearman nonparametric correlation

$\left({ }^{*}\right)$ Correlation is significant at the 0.01 level (two-tailed)

$\left({ }^{\star}\right)$ Correlation is significant at the 0.05 level (two-tailed). 
TABLE 5

ANOVA - age status $(\mathrm{n}=56)$

\begin{tabular}{lllllll}
\hline FACTOR & GROUPS & $\begin{array}{l}\text { SUM OF } \\
\text { SQUARES }\end{array}$ & DF & MS & F & Sig \\
\hline Integrating & Between & 0.255 & 2 & 0.127 & 0.275 & 0.760 \\
& Within & 24.074 & 52 & 0.463 & & \\
Avoiding & Between & 0.621 & 2 & 0.311 & 0.304 & 0.739 \\
& Within & 51.025 & 50 & 1.021 & & \\
Dominating & Between & 6.428 & 2 & 3.214 & 4.039 & 0.023 \\
& Within & 42.177 & 53 & 0.796 & & \\
Obliging & Between & 0.371 & 2 & 0.186 & 0.360 & 0.699 \\
& Within & 27.323 & 53 & 0.516 & & \\
Compromising & Between & 0.845 & 2 & 0.422 & 0.920 & 0.405 \\
& Within & 23.405 & 51 & 0.459 & & \\
\hline & & & & & & \\
& & & & & &
\end{tabular}

TABLE 6

Directional measures: age-status $(\mathrm{n}=56)$

\begin{tabular}{ll}
\hline FACTOR & ETA VALUE \\
\hline Integrating & $0.102^{*}$ \\
Avoiding & $0.110^{*}$ \\
Dominating & 0.364 \\
Obliging & $0.116^{*}$ \\
Compromising & $0.187^{*}$ \\
\hline
\end{tabular}

Evaluation of the descriptive statistics, application of the Analysis of Variance (ANOVA) and the directional measures revealed that except for the dominating conflict-handling style the remaining styles of managing interpersonal conflict are used to the same extent by the different age groups.

Table 7 contains the parametric (Pearson) and non-parametric (Spearman) inter-correlations for the different age groups. Comparison of the Pearson and Spearman inter-correlations reveal that a consistency exists, except for the age group 45 years and older (dominating) with correlation differences of $\mathrm{r}=-0.572$ at $p<0.01$ and Srho $=-0.382$ at $p<0.05$. The same is registered for obliging where $r=-0.446$ at $p<0.01$ and Srho $=-0.389$.

Analysing the Pearson correlation reveals that a significant negative correlation exists between the dominating and integrating conflict-handling styles $(-0.740 ; 36-45$ years and $-0.572 ; 45+$ years). Moderate negative relations are experienced between obliging, compromising and dominating variables with $\mathrm{r}=0.511, \mathrm{r}=0.446$ and $\mathrm{r}=0.606, \mathrm{r}=0.496$ at $\mathrm{p}<0.01$ respectively. Strong positive correlations exist between integrating, obliging and compromising. Closer scrutiny of the correlations and age groups reveals that in the age group 36 years and younger strong correlations are only recorded between compromising and obliging. It thus seems as if the younger owners/managers of small businesses are more inclined to focus on problem solving in a collaborative fashion, with a moderate to high concern for self and others. There can, however, also be a low concern for self as well as the other party where inaction, withdrawal or ignoring may occur with a correlation between compromising and obliging factors.

\section{DISCUSSION}

The combined objective of this exploratory study was to determine how gender and age variables affect the type of conflict-handling styles that are used during interpersonal conflict situations in the workplace.

The results did not support the first hypothesis which stated that males and females do not use the various conflict-handling styles to the same extent. It became clear that owners/managers of small businesses, whether male or female, use all the different conflict-handling styles to the same extent. However, the integrating style did have a small effect-size, which indicated that females tended to be more integrating than males, although no statistical significant difference could be proven. These
TABLE 7

Correlations of chs's according to age group in small businesses

\begin{tabular}{|c|c|c|c|c|c|c|}
\hline & 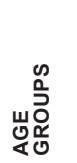 & 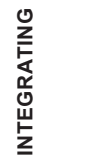 & 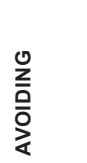 & 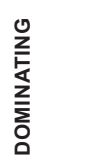 & $\begin{array}{l}0 \\
\frac{0}{2} \\
0 \\
10 \\
0\end{array}$ & 잉 \\
\hline$r$ & -36 & - & & & & \\
\hline Srho & & - & & & & \\
\hline$r$ & $36-45$ & - & & & & \\
\hline Srho & & - & & & & \\
\hline$r$ & $45+$ & - & & & & \\
\hline Srho & & - & & & & \\
\hline r & -36 & -0.253 & & & & \\
\hline Srho & & -0.073 & & & & \\
\hline r & $36-45$ & 0.038 & & & & \\
\hline Srho & & -0.031 & & & & \\
\hline r & $45+$ & -0.341 & & & & \\
\hline Srho & & -0.268 & & & & \\
\hline r & -36 & -0.460 & 0.295 & & & \\
\hline Srho & & -0.367 & 0.307 & & & \\
\hline r & $36-45$ & $0.740^{\star *}$ & 0.265 & & & \\
\hline Srho & & $-0.710^{\star \star}$ & 0.167 & & & \\
\hline r & $45+$ & $-0.572^{* *}$ & -0.158 & & & \\
\hline srho & & -0.382 & -0.204 & & & \\
\hline r & -36 & 0.373 & 0.314 & -0.167 & & \\
\hline Srho & & 0.467 & 0.418 & -0.268 & & \\
\hline r & $36-45$ & $0.785^{\star *}$ & 0.161 & $-0.511^{*}$ & & \\
\hline Srho & & $0.849^{* *}$ & 0.171 & $-0.544^{*}$ & & \\
\hline r & $45+$ & 0.328 & 0.397 & $-0.446^{*}$ & & \\
\hline srho & & 0.201 & 0.379 & -0.389 & & \\
\hline r & -36 & $0.885^{* *}$ & -0.025 & -0.340 & $0.563^{*}$ & - \\
\hline Srho & & $0.931^{* *}$ & 0.087 & -0.347 & $0.593^{*}$ & - \\
\hline r & $36-45$ & $0.731^{\star *}$ & 0.165 & $-0.606^{*}$ & $0.722^{\star \star}$ & - \\
\hline Srho & & $0.846^{* *}$ & 0.006 & $-0.740^{* *}$ & $0.767^{* *}$ & - \\
\hline r & $45+$ & 0.420 & -0.191 & $-0.496^{\star}$ & 0.146 & - \\
\hline Srho & & 0.256 & -0.145 & $-0.463^{*}$ & 0.125 & - \\
\hline
\end{tabular}

$=$ Pearson parametric correlation

(*) Correlation is significant at the 0.05 level (two-tailed).

findings support the results of Rahim (1983) that females have a more cooperative (integrating/collaborating) orientation to conflict handling than males. However, Bedell \& Sistrunk (1973) concluded that females are more competitive (dominating). Brewer et al. (2002) found in their study that obliging (accommodating) and avoiding are more consistent with females.

With regard to males the use of the dominant (competitive) conflict-handling style was verified by this study and the others mentioned above. Portello \& Long's study (1994) also reported masculine individuals adopting a dominating style. In the present study the dominating behaviour appears consistent with a masculine gender role, whilst use of the obliging and avoiding conflict-handling styles appears consistent with a female gender role. It should be noted again that it was found that a significant positive correlation exists between compromising and obliging $(r=0.584, p<0.05)$ for females. In the case of males a strong negative correlation exists between the dominating and integrating style $(\mathrm{r}=-0.630, \mathrm{p}<0.01)$, and compromising $(\mathrm{r}=-0.345$, $\mathrm{p}<0.05)$.

Considering the age groups and the types of conflict-handling styles they used in interpersonal conflict situations, the Pearson and Spearman inter-correlations were applied. Both methods were used to verify the ranked data. The results supported the second hypothesis which stated that conflict-handling styles were used to a different extent among various age groups. Evaluation of the statistics as portrayed in the different tables revealed that apart from the dominating conflict-handling style the 
remaining styles are used to the same extent by the different groups. The older the participants are, the less dominating or competitive the style used.

Comparison of the inter-correlations of the gender and age groups' conflict-handling styles reveal that the integrating variable for males had a significant negative correlation with the dominating factor and significant positive correlation with the obliging and compromising factors. The correlations of the compromising factor for the male gender also had negative and positive correlations with integrating, dominating and obliging. This also corresponds with that of the age groups. Females only recorded a negative correlation between the dominating and obliging factors and a positive correlation between the compromising and obliging factors. This corresponds with the findings of the age groups. It thus seems that a relationship exists between conflict-handling styles and gender and age. A contradiction, however, does exist with regard to the fact that females have a more integrating or collaborating approach to conflict handling. When their age is taken into consideration, it appears that the younger they are, the more they tend to make use of the dominating conflict-handling style to manage conflict situations. A clear answer to this difference could not be found. A study conducted by Antonioni (1998) revealed that in general age and gender had little relationship with the variance in conflict-handling styles. His manager sample coefficients for both age and gender were non-significant as was the case for a student sample. Age was significantly associated with only two of the five styles, namely the use of integrating (Beta $=0.12$ $<0.05$ ) and avoiding (Beta $=0.15<0.01)$ styles. In the present study integrating, avoiding and obliging all had small effect sizes.

\section{Limitations}

The generalisability of the results is limited by the relative small sample size and the demarcation of the study to a restricted geographic area. Furthermore findings were based on a purely Caucasian (White) group of participants. Amongst the group of 56 respondents no Asians, Black Africans or Coloureds were to be found. As such no cultural influences could be included in the evaluation of the conflict-styles used by the participants. Other race groups may have had different outcomes with regard to age and gender. Another limitation is that a convenience sample was used. The absence of randomisation for control could affect the data. A further limitation could be the fact that only owners/managers' conflict-handling styles toward subordinates were studied. No attempt was made to explore and distinguish behavioural characteristics that may have been applicable to academic qualifications or industry groupings.

\section{CONCLUSION}

This study provides insights into conflict-handling styles and their application by owners/managers of small firms based on gender and age variables. In some instances the results are compelling and consistent with other studies and in other cases, as shown in this study, the findings differ.

What has become evident is that although the variance in styles in which conflict is managed by gender role and age respectively was not particularly large, it was established that females made use of the integrating styles on a more frequent basis than males. The other conflict-handling styles showed no significant difference in usage between the two genders. Negative and positive inter-correlations with regard to the conflict-handling styles were registered for both genders with more significant relations existing in the styles used by males.

With regard to age it was determined that except for the dominating style other conflict-handling styles were used to the same extent by different age groups. It has also become clear that with the younger age group a strong correlation exists between compromising and obliging.
The fact that the integrating and dominating styles have been prominent amongst the five conflict-handling styles calls for some further remarks. It should be noted that the dominating style of managing conflict is considered to be the worst style. It increases frustration and leaves residual frustration which is likely to cause further conflict (Rahim, 1992).

Superiors who use the dominating style are also, according to Van der Vliert, Euwema \& Huismans (1995), less effective with their subordinates. Utley, Richardson \& Pilkington (1989) have found that a relationship exists between the need for aggression and a dominating or forcing style. Individuals using the latter style may not be open to new experiences. With the integrating style, information needs and interests are shared openly, whilst the dominating style may be a demonstration of power. High levels of emotional stability may also be required when using the dominating style (Antonioni, 1998). It appears from discussions earlier in this study as well as the results given, that owners/ managers of small businesses should preferably use a conflict strategy with low levels of dominance and even avoidance. The most frequently used conflict-management style should be collaboration. Sorenson's 1994 study suggests that businesses that produce the highest outcomes have developed a norm of collaborating.

In conclusion it can be stated that relatively few studies have been done to evaluate different aspects of conflict dynamics in small businesses. It is believed that this study, though exploratory in nature, has given a more usable picture of interpersonal conflict with regard to gender and age and the application of different conflict-handling styles. Future research on a much larger scale and with more participants is deemed necessary. Applying such a study to different cultures and races may also divulge valuable information if also applied to conflict-handling styles used by employees of small businesses in interpersonal workplace conflict situations. Integration of such knowledge into training programmes would not only enhance the quality of working relationships, but would also help to decrease conflict and enhance work performance and productivity.

\section{REFERENCES}

Antonioni, D. (1998). Relationship between the big five personality factors and conflict management styles. International Journal of Conflict Management, 9(4), 336-354.

Amason, A.C. (1996). Distinguishing the effects of functional and dysfunctional conflict on strategic decision making. Academy of Management Journal, 39, 123-148.

Applebaum, H., Abadallah, C.S. \& Shapiro, B. (1999). The selfdirected team: A conflict management analysis. Team Performance Management, 5(2), 60-77.

Bedell, J. \& Sistrunk, F. (1973). Power, opportunity costs and sex in a mixed-motive game. Journal of Personality and Social Psychology, 25, 219-226.

Ben-Yoav, D. \& Banai, M. (1992). Measuring conflict management styles: A comparison between the MODE and ROCinstruments using self and peer ratings. International Journal of Conflict Management, 3, 237-247.

Blake, R.R. \& Mouton, J.S. (1964). The Managerial Grid. Houston, Texas: Gulf.

Bodtker, A.M. \& Jameson, J.K. (2001). Emotion in conflict formation and its transformation: Application to organizational conflict management. International Journal of Conflict Management, 12(3), 259-276.

Boles, J. (1996). Influences of work-family on job satisfaction and quitting intentions among business owners. The case of family-operated business. Family Business Review, 9(2), 61-74.

Brenner, D.C., Tomkiewicz, J. \& Schein, V N. (1989). The relationship between sex role stereotypes and requisite management characteristics revisited. Academy of Management Journal, 32, 662-669. 
Brewer, N., Mitchell, P. \& Weber, N. (2002). Gender role organizational status, and conflict management styles. The International Journal of Conflict Management, 13 (1), 78-94.

Churchill, N.C. (1983). Entrepreneurs and their enterprises: A stage model. In G. A. Hornaday, G. Timmons \& K.H. Vesper (Eds.). Frontiers of Entrepreneurship Research. Wellesley, M. A. Babson.

Davis, P.S. \& Harveston, P.D. (2001). The phenomenon of substantive conflictin thefamily firm: A cross-organizational study. Journal of Small Business Management, 39(1), 13-40.

Euwema, M.C. \& Van de Vliert, E. (1990). Gedrag en escalatie bij hiërarchisch conflicte. (Behaviour and the escalation in hierarchical conflicts). Toegepaste Sociale Psychologie, 4 28-41.

Filbeck, G. \& Smith, L. L. (1997). Team building and conflict management strategies for family business. Family Business Review, 10(4), 339-352.

Gross, M.A. \& Guerrero, L.K. (2000). Managing conflict appropriately and effectively: An application of the competence model to Rahim's organizational conflict styles. The International Journal of Conflict Management, 11(3), 200-226.

Grote, J. (2003). Conflicting generations: A new theory of family business rivalry. Family Business Review, 16(2), 113-127.

Hall, J. (1969). Conflict Management Survey. Conroe, Texas: Telometrics International.

Havenga, W. (2005). A comparative analysis of conflict dynamics within public and private sector organisations. $\mathrm{PhD}$ dissertation. North-West University, South Africa.

Huey-Wen Chou, \& Ying-Jung Yeh. (2007). Conflict, conflict management, and performance in ERP teams. Social Behaviour and Personality, 35(8), 1035-1048.

Welsh, J.A. \& White, G.F. (1981). Converging on Characteristics of Entrepreneurship Research. Wellesley, M. A. Babson.

Jehn, K.A. (1997). A qualitative analysis of conflict types and dimensions in organization groups. Administrative Science Quarterly, 42, 530-557.

Jehn, K.A. (1995). A multimethod examination of the benefits and detriments of intragroup conflict. Administrative Science Quarterly, 40, 256-282.

Jehn, K.A., Northcraft, G. \& Neale, M. (1999). Why differences make a difference: A field study of diversity, conflict, and performance in work groups. Administrative Science Quarterly, 44, 741-763.

Lotriet, W., Crafford, A., \& Visser, D. (2001). Die verband tussen interpersoolike behoefles en konflikhantering style. Journal of Industrial Psychology, 27(2), 42-50.

Meyer, S. (2004). Organizational response to conflict: Future conflict and work outcomes. Social Work Research, 28(3), 183-190.

Nauta, A \& Kluwer, E. (2004). The use of questionnaires in conflict research. International Negotiation, 9, 457-470.

Nunnally, J.C. \& Bernstein, I.H. (1994). Psychometric Theory. New York. McGraw-Hill.

Pearson, A.W., Ensley, M.D. \& Amason, A.C. (2002). An assessment and refinement of John's intergroup conflict scale. Journal of Conflict Management, 13, 110-126.

Pelled, L.H., Eisenhardt, K.M. \& Xin, K.R. (1999). Exploring the black box: An analysis of work group diversity, conflict and performance. Administrative Science Quarterly, 44, 1-28.

Portello, J.Y. \& Long, B.C. (1994). Gender orientation, ethical and interpersonal conflicts and conflict handling styles of female managers. Sex Roles, 31, 683-701.

Powell, G. N. \& Butterfield, D. A. (1979). The good manager Masculine or androgynous? Academy of Management Journal, $22,395-403$.
Rahim, M.A. (1983). A measure of styles of handling interpersonal conflict. Academy of Management Journal, 26, 368-376.

Rahim, M.A. (1986). Managing Conflict in Organizations. New York: Preager.

Rahim, M. A. (1992). Managing conflict in Organizations. New York: Praeger.

Rahim, M.A. \& Magner, N.R. (1995). Confirmatory factor analysis of the styles of handling interpersonal conflict: First-order factor model and its intervariance across groups. Journal of Applied Psychology, 80, 122-132.

Rahim, M.A. (2002). Toward a theory of managing organizational conflict. The International Journal of Conflict Management, 13(3), 206-235

Rahim, M.A. (2001). Managing Conflict in Organizations. Westpart CT. USA: Quorum Books.

Robbins S.P. (1998). Organizational behaviour. New Jersey: Simon and Schuster.

Ross, R.S. \& Ross, J.R. (1989). Small Groups in Organizational Settings. Englewood Cliff, N.J: Prentice Hall.

Slabbert, A.D. (2002). Managerial modes of conflict resolution in the banking industry. South African Journal of Economics and Management Sciences, 5(1), 258-270.

Sorenson, R.L. (1999). Conflict management strategies used in successful family business. Family Business Review X11, (2), 133-146.

Sorenson, P. \& Hawkins, K. (1995). Gender, psychological type and conflict style preference. Management Communication Quarterly, 9, 115-127.

Sutschek, L.B. (2001). Conflict resolution style and experience in management: Moderating the effects of gender._Journal of Conflict Management, 11, 110-122.

Suzuki, M. \& Hayashi, Y. (2001). Conflict management and organizational attitudes among Japanese: Individual and group goals and justice. Asian Journal of Social Psychology, 4, 93-101.

Thomas, K.W \& Kilmann, H.R. (1974). Thomas-Kilman Conflict MODE Instrument. New York: Xicom.

Thomas, K.W. \& Kilmann, R.H. (1978). Comparison of four instruments measuring conflict behavior. Psychological Reports, 42, 139-145.

Ting-Toomey, S. (1985). Toward a theory of conflict and culture. In W.B. Gudykunst, L.P. Stewart \& S. Ting-Toomey (Eds.). Communication Culture and Organization Processes, 71-85. Beverly Hills, CA: Sage.

Utley, M., Richardson, D., \& Pilkington, C. (1989). Personality and interpersonal conflict management. Personality and Individual Differences, 10, 287-293.

Van de Vliert, E. (1994) Agreeableness and activeness as components of conflict behaviors. Journal of Personality and Social Psychology, 66, 674-687.

Van de Vliert, E. (1996). Interventions in conflicts. In M G. Schabruco, G.A.M. Winnbust \& C.L. Cooper (Eds.). Handbook of Work and Health Psychology. New York: Wiley \& Son, $405-425$.

Vilaseca, A. (2002). Stakeholder role in family business: Conflict of interests and objectives between non-employed shareholders and top management team. Family Business Review XY, (4), 299-320.

Vinger, G. \& Cilliers, F. (2006). Effective transformational leadership behaviours for managing change. S.A. Journal of Human Resource Management, 4(2), 1-9.

Weider-Hatfield, D. \& Hatfield, G.D. (1995). Relationships among conflict management styles, levels of conflict and reactions to work. The Journal of Social Psychology, 135(6), 687-698. 